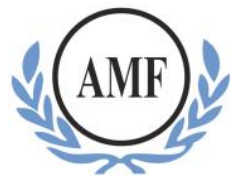

\title{
Saúde mental no ambiente organizacional: os desafios de uma comunicação eficaz e não violenta com os trabalhadores
}

\author{
Eraldo Carlos Batista ${ }^{1}$ \\ Sarah de Andrade Moretti ${ }^{2}$
}

\begin{abstract}
Resumo: A comunicação não violenta é uma ferramenta bastante útil na resolução de conflitos, haja vista que, por intermédio de sua metodologia inovadora, leva em consideração comportamentos, sentimentos, percepções, necessidades pessoais de si e do outro. $\mathrm{O}$ objetivo deste artigo foi analisar a produção literária sobre comunicação organizacional e investigação de modo eficaz a fim de promover o bem-estar geral através da comunicação eficiente e não violenta. Os estudos mostraram que a comunicação não violenta inaugura um modo de comunicação que proporciona a possibilidade de uma conexão real em nossas interações. Ao trazer a humanização à tona, com todas as suas necessidades e vulnerabilidades, ela se torna uma valiosa ferramenta de resolução de conflitos e de habilidades sociais.
\end{abstract}

Palavras-chave: Comunicação; Comunicação não violenta; Organização.

\section{Mental Health In The Organizational Environment: The Challenges Of Effective And Non-Violent Communication With Workers}

\begin{abstract}
Non-violent communication is an extremely useful tool in conflict resolution, given that, through its innovative methodology, it considers behaviors, feelings, perceptions, personal needs of oneself and the other. The aim of this article was to analyze literary production on organizational communication and research on effective ways to promote general well-being through efficient and non-violent communication. Studies have shown that non-violent communication opens a way of communication that provides the possibility of a real connection in our interactions, by bringing humanization to the surface. With all its needs and vulnerabilities, it becomes a valuable conflict resolution tool and social skills.
\end{abstract}

Keywords: Communication; Non-violent communication; Organization.

Salud mental en el entorno organizacional: los desafíos de una comunicación eficaz y no violenta con los trabajadores

\footnotetext{
${ }^{1}$ Doutor em Psicologia Social pela Pontifícia Universidade Católica do Rio Grande do Sul - PUCRS, Tangará da Serra, Mato Grosso, eraldo.cb@ hotmail.com.

${ }^{2}$ Graduação em Psicologia pela Universidade Paulista - UNIP, Santos, Especialização em Terapias Cognitivas pela Cognitiva Scientia, sarahdeandrademoretti@gmail.com.
} 
Resumen: La comunicación no violenta es una herramienta de gran utilidad en la resolución de conflictos, ya que, a través de su innovadora metodología, considera comportamientos, sentimientos, percepciones, necesidades personales de uno mismo y del otro. El objetivo de este artículo fue analizar la producción literaria sobre comunicación organizacional y la investigación sobre formas efectivas de promover el bienestar general a través de una comunicación eficiente y no violenta. Los estudios han demostrado que la comunicación no violenta abre una vía de comunicación que brinda la posibilidad de una conexión real en nuestras interacciones, al traer la humanización a la superficie. Con todas sus necesidades y vulnerabilidades, se convierte en una valiosa herramienta de resolución de conflictos y habilidades sociales.

Palabras clave: Comunicación; Comunicación no violenta; Organización.

\section{Introdução}

A comunicação tem uma enorme influência na evolução da espécie humana, pois serviu e ainda serve como um meio essencial e importante de integração de grupo e de transmissão de conhecimento, promovendo o desenvolvimento pessoal e coletivo. Cardoso e Mendes (2018) narram uma história que foi difundida no meio popular sobre Michelangelo, onde contam que o artista, após concluir sua escultura Moisés, ficou tão impressionado com a perfeição que a questionou sobre seu silêncio e pediu que ela falasse, deixando a célebre frase para a posteridade: "Por que não falas? Fala!". Os autores encerram a história descrevendo que, em face do silêncio mantido pela estátua, Michelangelo ficou desapontado e lhe martelou o joelho. No entendimento dos autores, essa história se faz relevante para a questão da comunicação e da linguagem pela suposta proximidade do pensamento do artista entre a linguagem e o espírito humano, indicando que a linguagem faria parte da natureza humana.

A comunicação é um processo que consiste na transmissão de informações codificadas por um interlocutor através de um canal a ser decodificado por um receptor, portanto, há a interpretação de uma determinada mensagem. Assim, a fluidez do ato comunicativo deve ser entendida como uma via de mão dupla, onde, por um lado, existe um indivíduo que pretende transmitir ideias, criando condições para seu amplo entendimento, e, por outro, há outro indivíduo, que escuta e compreende as informações transmitidas.

As competências de comunicação de um indivíduo são utilizadas no modo de expressão e comunicação com seu grupo social, com seus superiores ou subordinados no trabalho, com seus clientes, na cooperação do trabalho de equipe, no diálogo, nas negociações e na comunicação em geral. Nota-se que um indivíduo pode ser um 
comunicador competente em uma linha de comunicação específica, mas pode não ser competente em outra.

Chama-se a atenção para o fato de que a comunicação eficiente é um dos maiores desafios, se não o maior, no mundo profissional e social em geral. Também se deve ter em mente que a maneira como nos comunicamos se torna um tipo de identidade. Este fato pode ser exemplificado em expressões como: "Ele é um desesperado, fala tão rápido e sem parar que eu mal consigo entendê-lo", "Ela é muito brava, ela está sempre gritando e não ouve ninguém", "Ele é muito gentil, sempre tem algo de bom para dizer sobre todos", "Ela é tão calma e tem uma maneira tão serena de dizer que até esqueço de problemas quando falo com ela" etc.

O poder contido nas palavras pode de fato fazer com que as pessoas, em geral, sintam-se valorizadas ou arrasadas. É importante ter sempre em mente que as palavras trazem afetos, que podem ser positivos ou não. Em geral, as pessoas podem esquecer o nome de um indivíduo, mas lembram-se vividamente de como se sentiam em relação a ele. Um bom exemplo disso são nossas memórias de infância: "Havia uma menina na minha sala de aula que sempre era boa comigo", "Quando eu era moleque tinha um vizinho na minha rua que sempre me maltratava", "A moça da padaria sempre me falava uma coisa legal", "O tio da banca de jornal sempre tinha uma história engraçada para me contar".

A comunicação divide-se em quatro tipos diferentes, sendo eles: comunicação verbal, comunicação não verbal, comunicação escrita e comunicação visual. Cada um desses tipos de comunicação afeta os mínimos aspectos da vida.

O que pode ser facilmente observado no comportamento humano geral é que: evitamos estar próximos de pessoas que nos criticam, diminuem ou nos ofendem; nós simplesmente não gostamos de tê-las por perto, fugimos e nos protegemos delas, e não raramente as atacamos de volta, visto que elas nos trazem sentimentos desagradáveis. Em alguns casos, não é sequer necessário que a pessoa verbalize sua crítica, basta o vislumbre daquele olhar fulminante direcionado ou então aquele riso de deboche e pronto, o dano no relacionamento já foi causado.

A comunicação acontece o tempo todo. Mesmo as pessoas que falam pouco estão se comunicando com o grupo de algum modo; lembra-se do olhar fulminante ou do riso de deboche? Portanto, mesmo o silêncio já é alguma comunicação. Por exemplo, você já deve ter ouvido falar que uma determinada situação foi tão intensa para alguém que a pessoa não 
conseguiu nem mesmo dizer nada naquela hora. Este exemplo mostra que aquele silêncio não era vazio, na verdade, estava repleto de significado e emoção e comunicava algo.

Segundo Watzlawick, Beavin e Jackson (2007), há no ser humano uma impossibilidade de não se comunicar, explanando o fato de que todo comportamento é uma forma de comunicação. Assim, do mesmo modo que não existe um não comportamento, também não existe uma não comunicação. Logo, é impossível não se comunicar. Deve-se também considerar que os autores denominaram como metacomunicação a comunicação não verbal ao que é percebido, ou seja, aquilo que é sentido no clima do grupo. Denota-se que o trabalho pode ser um agente causador de felicidade e satisfação, mas também pode vir a ser fonte de sofrimento.

Observa-se que muitos indivíduos veem seu ambiente de trabalho como uma tortura diária, e travam uma verdadeira batalha para se manterem mentalmente equilibrados neste espaço. Entre algumas das queixas constantes estão as exigências irreais, líderes confusos, pouca clareza nas definições das funções laborais, cobranças ameaçadoras, intimidação, comunicação ineficaz, humilhação e assédio psicológico. Clarifica-se que o trabalhador pode sofrer com um ou mais dos itens citados e, com isso, ir acumulando seus recursos internos de modo que, em algum momento, possa até mesmo vir a desenvolver um desequilíbrio físico e emocional, podendo acarretar sérios problemas para sua saúde. Algumas das consequências de um ambiente profissional tóxico são: estresse, ansiedade, síndrome de Burnout, transtorno de pânico e transtornos mentais relacionados ao consumo de álcool e drogas.

Evidencia-se que o estresse de cada membro do grupo afeta os outros membros. Assim, o estresse de um único membro do grupo pode, de fato, ser o reflexo do sofrimento coletivo. Por outro lado, um ambiente positivo pode permitir que características positivas de seus membros sejam manifestadas e amplificadas, o que, por sua vez, potencializa os resultados do grupo.

Atualmente nota-se que casos de transtornos psiquiátricos e doenças mentais no ambiente de trabalho estão crescendo e são alguns dos fatores que mais afastam profissionais de suas atividades. Conforme Prates (2017), no Brasil este tipo de adoecimento vem crescendo rapidamente, observando os dados da Previdência Social, que registrou em 2016 o afastamento de 75,3 mil trabalhadores em razão de quadros depressivos, o que representa $37,8 \%$ de todas as licenças médicas motivadas por transtornos mentais e comportamentais no mesmo ano. Em 2016, foram registrados mais de 199 mil casos de pessoas que se 
ausentaram de empresas públicas e privadas por sofrerem transtornos psiquiátricos e doenças mentais ligadas ao exercício profissional.

Evidencia-se então que, para evitar que estes adoecimentos ocorram, as empresas precisam criar necessariamente um ambiente saudável para todos. Uma comunicação falha ou inapropriada é considerada como um fator de risco para a saúde do trabalhador, de acordo com a OMS (2017). Sublinha-se que a saúde mental dos funcionários de uma organização é grandemente prejudicada quando as práticas de gestão e de comunicação são inadequadas. Para a OMS (2017), as empresas podem adotar intervenções como parte de uma estratégia integrada de saúde e bem-estar que incluam a prevenção, a identificação precoce, o apoio e a reabilitação dos trabalhadores.

A falta de habilidade em comunicação, além de poder ser prejudicial para a saúde mental dos trabalhadores, também fará com que, no caso do líder, seja impossível liderar o ambiente corporativo de modo eficaz e adequado. No caso dos trabalhadores, a pouca competência em comunicação pode acarretar com que o profissional não seja reconhecido ou mesmo que não consiga desempenhar suas funções adequadamente, o que o torna um profissional de pouca produtividade.

O processo comunicativo e sua relação com o ambiente organizacional envolvem diferentes facetas que serão exploradas nestas páginas; entre elas trataremos dos temas de percepção, conflito, mudança organizacional, integração, feedback e comunicação não violenta.

\section{Fundamentação Teórica}

\subsection{Percepção}

Segundo Macedo Filho (2003), a pessoa não somente vê, mas principalmente percebe o objeto que observa de forma particular a si mesma, que, por sua vez, é um modo único de perceber outro ser humano. $\mathrm{O}$ autor pontua que nos delineamentos organizacionais, a percepção e suas possíveis distorções são elementos de grande relevância para o estabelecimento do clima, das relações, da qualidade de vida no trabalho, entre outros fatores.

Macedo Filho (2003) pontua que o indivíduo percebe e é percebido pelos outros. Indicando, assim, a existência de uma relação "percebedor-percebido", sendo que, tal 
relação, segundo o autor, é um fator demasiadamente importante para o autoconhecimento. Elucida-se que conforme Katz e Kahn (1974), a posição ocupada pelo colaborador no espaço organizacional pode limitar seu acesso à organização de um modo global, podendo, também, limitar a quantidade e a qualidade de informações que irá receber, o que pode acarretar percepções errôneas.

Pontua-se que percepções errôneas em geral levam a compreensões também errôneas; em face de tantos equívocos, não se torna imprevisível supor que existam conflitos e falhas na comunicação que, por sua vez, podem gerar uma produtividade menor.

\subsection{Conflito}

O conflito é um processo de oposição e confronto, podendo ocorrer tanto entre pessoas como em grupos (WAGNER, 1999). É a existência de ideias, sentimentos, atitudes, interesses antagônicos, diferentes, que colidem, que se chocam (CHIAVENATO, 1992).

Há várias formas de conflito; por exemplo, o conflito interno e o externo, de relacionamento pessoal e interpessoal, entre outros. Existem quatro condições que antecedem o conflito, sendo estas: a ambiguidade de papel, os objetivos concorrentes, os recursos compartilhados e a interdependência de atividades (CHIAVENATO, 1992). O autor expressa que existem várias formas de administração de conflitos, como: evitação/fuga; acomodação/suavização; competição/comando autoritário; concessão/acordo; e, por fim, colaboração ou resolução dos problemas.

Felippe (2012) expõe que os conflitos atravessam o cotidiano e, geralmente, envolvem questões como a tomada de decisão. A autora repousa na concepção de que o conflito também pode ser produtivo para o desenvolvimento da organização. Revela-se, ainda, que a identificação de conflitos, dentro de uma organização, deve acarretar um movimento a fim de eliminá-los ou de administrá-los. A autora expõe que um poderoso auxiliar na administração dos conflitos é a Negociação. O conflito pode ser uma arma poderosa de desenvolvimento da organização e das pessoas, quando bem administrado (FELIPPE, 2012).

Diante de uma situação conflituosa, deve-se enfocar a causa real do conflito. Neste sentido, é possível aproveitar a emergência do conflito como uma oportunidade para alcançar o melhor resultado possível, que, em geral, é o que todos os envolvidos desejam. 
Fustier (1982) remete que os conflitos podem ser classificados, em linhas gerais, segundo os contrários: a natureza do conflito e suas causas.

\subsection{Mudança Organizacional}

Segundo Vieira e Vieira (2003), a mudança organizacional deve ser vista como um processo permanente, uma necessidade de atualização que gera atualização. Para Fonseca (2000), mesmo quando as mudanças sejam percebidas como necessárias, caso ocorram de modo rápido e brusco, dificilmente são recebidas de forma consensual e podem despertar pouco comprometimento dos membros. Mudanças muito rápidas e bruscas podem, também, produzir efeitos contrários, provocando resistência, conflitos, ressentimentos, mágoas e até sabotagens.

Ghani et al (2002) explana que a mudança planejada pode ser compreendida como um esforço proativo da empresa, envolvendo seus membros e redefinindo suas atribuições, para, assim, atingir o objetivo proposto pela organização. Conforme Acuña e Fernández (1995), a iniciativa de uma mudança segue a intenção de resolver problemas, para que, assim, as organizações possam ter um melhor desempenho.

\subsection{Integração}

Treinamentos de integração, segundo Silva, Nascimento e Botelho (2013), são positivos tanto para o desempenho do funcionário quanto da empresa, haja vista que uma vez que o colaborador compreende seu papel na estrutura organizacional, ele se envolve mais ativamente no processo, e passa a fazer parte da organização de modo mais efetivo, agindo, assim, de modo mais ativo nos processos organizacionais. Segundo tais autores, quando o colaborador se sente um membro pertencente e participativo nos resultados da organização, ele pode responder de forma mais rápida e positiva na realização de suas atividades dentro da estrutura em que está enquadrado.

Entretanto, se ocorrer o oposto, ele pode se sentir desorientado, o que o levaria a fazer o trabalho de modo mecânico, sem ter o conhecimento do significado de sua atividade na contribuição do resultado da organização. Araújo e Garcia (2010) endossam que oferecer um treinamento para um colaborador é sinônimo de um regime que oportuniza condições mais favoráveis à aprendizagem e à plena integração dos membros na organização. 
Há no ser humano uma tendência natural em fugir do sofrimento e sentimentos de exclusão nos fazem sofrer. Pelo contrário, há uma espécie de alegria neuroquímica quando nos sentimos realmente conectados com alguém. Brandão (2011) expõe que nenhum indivíduo vive isolado, logo, não é possível compreender o comportamento do sujeito sem considerar a influência que este sofre do outro. Para a autora, estabelecemos relações em que cada uma das pessoas envolvidas tem suas intenções particulares, daí a necessidade de os membros entrarem em entendimento para que o objetivo do grupo seja alcançado. A autora afirma que o alcance do objetivo depende necessariamente desse relacionamento.

Na concepção de Fiorelli (2000), a integração aumenta o conhecimento por meio da reciprocidade, tornando mais fácil aproveitar as habilidades de cada membro e agindo como fator de neutralização dos pontos fracos.

\subsection{Feedback}

O processo de comunicação deve incluir o feedback. Pois sem o feedback a comunicação é unilateral; já no caso da informação de retorno, a comunicação é considerada bilateral (ROBBINS, 2002). Assim, o feedback proporciona que o transmissor saiba se o receptor obteve a informação de forma adequada. Sobre esse fenômeno, Davis e Newstron (2001) informam que a comunicação bilateral só é possível se for intermediada pelo feedback. Pois, segundo os autores, o feedback é uma ferramenta imprescindível para atingir a excelência na comunicação corporativa. Conclui-se, portanto, que o uso do feedback contribui efetivamente para a gestão de pessoas, para o aumento da produtividade e para o crescimento das organizações.

Para Benítez (2001), quanto maior for o uso do feedback, mais eficaz tende a ser o processo de comunicação, pois esta ferramenta permite aos gestores saberem se suas instruções foram compreendidas e aceitas. Atualmente observam-se quatro tipos de feedback, sendo eles: positivo, corretivo, insignificante e ofensivo. No feedback positivo, o objetivo seria o de reforço para aquilo que se deseja que ocorra novamente. No feedback corretivo, o objetivo seria o de corrigir aquilo que é considerado inadequado; muitas vezes esse tipo de feedback pode ser confundido como punitivo. Já no feedback insignificante, trata-se de algo sem relevância, o famoso "não fede e não cheira", e a pessoa que o recebe não consegue ter clareza do que foi transmitido. Por sua vez, o feedback ofensivo acaba desvalorizando e desqualificando aquele que o recebe, podendo, então, estimular sentimentos negativos e acarretar submissão ou desejos de vingança. 


\subsection{Engendramentos Da Comunicação Não Violenta}

Através de suas próprias experiências, o psicólogo social Rosenberg (2006) elaborou sua metodologia e cunhou o termo Comunicação Não Violenta-CNV. A CNV, de acordo com o autor, pode funcionar como um norteador na resolução e prevenção de conflitos, em vista de que a maior parte dos motivos dos conflitos ocorre necessariamente na forma como nos comunicamos, ou seja, o modo como falamos e ouvimos os outros, e ainda o modo como somos ouvidos pelas outras pessoas.

Dentre as condições apropriadas para que a comunicação tenha o efeito desejado, há o cuidado na maneira como o comunicado é expresso, em face de que ele deve de fato ser acessível e cognoscível ao ouvinte e deve esclarecer a situação. Seguindo esta lógica, compreende-se que o processo comunicativo possa ser alterado conforme haja mudanças na forma da comunicação, onde tais mudanças possam solucionar desentendimentos desnecessários e, num nível mais avançado, possa até mesmo evitar o início de conflitos. Rosenberg (2006) elucida que a metodologia da CNV pode contribuir grandemente para um melhor clima nas organizações, pois suas técnicas comunicativas promovem a humanização das relações profissionais, em face de que proporcionam empatia.

Observa-se que o uso da CNV pode proporcionar benefícios na vida cotidiana em geral, denotando que a CNV abre caminhos para que haja a escuta empática e um diálogo mais sincero, o que faz com que a comunicação flua de um modo menos tenso. Assim, neste processo comunicacional, podem ser expressas as necessidades dos envolvidos e encontradas as soluções. Pois, conforme o autor, sempre que não temos nossas necessidades satisfeitas, tendemos a pensar que há algo de errado com as outras pessoas.

Denota-se, ainda, que quando se está preso somente a um ponto de vista, no concernente às necessidades de apenas um dos lados do relacionamento, o terreno mostrase bastante fértil para o surgimento de mal-entendidos e conflitos; não obstante, quando há espaço para a troca e escuta das necessidades de todos, há mais flexibilidade para melhores resultados para ambos os lados.

A metodologia desenvolvida à luz dos delineamentos de Rosenberg (2006) apresenta quatro componentes, sendo eles: (1) Observação: trata-se de simplesmente observar o que a outra pessoa está dizendo ou fazendo e não fazer neste momento julgamentos de juízos e valores; (2) Sentimento: trata-se de identificar quais foram os sentimentos vivenciados a 
partir desta observação; (3) Necessidade: trata-se de reconhecer honestamente qual necessidade está ligada ao sentimento observado que não está sendo atendida; e (4) Pedido: trata-se de, após ter cumprido as três etapas anteriores, formular um pedido com clareza e objetividade.

\subsection{Aplicabilidade da CNV}

A CNV nasce no interior do indivíduo, no modo como interagimos com nós mesmos e com os outros, pois, sua metodologia desperta a compassividade e a empatia que, segundo o autor, são sentimentos inerentes ao ser humano (ROSENBERG, 2006). Entretanto, para o autor, apesar de em nossa natureza apreciarmos dar e receber com compaixão, aprendemos ao longo da vida muitos modos de "comunicação alienante da vida", que nos levam a nos comunicarmos e nos comportarmos de modo que fira aos outros e a nós mesmos. Em sua busca pelos motivos que levam o ser humano ao afastamento de seu estado compassivo natural, Rosenberg (2006) identificou como "comunicação alienante da vida" as especificidades do processo comunicacional que favorecem comportamentos violentos direcionados a nós mesmos e às outras pessoas.

Entre as especificidades da comunicação alienante da vida encontradas por Rosenberg (2006), temos: os julgamentos moralizadores; a negação da responsabilidade; o ato de tentar forçar as pessoas a fazerem algo - com exigências e ameaças, por exemplo; o pensamento baseado em "quem merece o quê"; e as raízes filosóficas e políticas.

O item julgamentos moralizadores trata de comparar e ajuizar aqueles que não agem de acordo com nossos valores como sendo pessoas más ou errantes; outros modos de

julgamentos moralizadores são comparações, rotulações, depreciação, críticas e insultos. Neste raciocínio, Rosenberg (2006) conclui que analisar as outras pessoas trata-se necessariamente de um modo de expressão de nossas próprias necessidades e valores. $\mathrm{O}$ autor expõe que nosso foco se concentra em analisar e identificar os níveis de erros alheios ao invés de nos concentrarmos nas necessidades, nossas e das outras pessoas, que não estão sendo atendidas.

Para tanto, exemplifica muito bem sua teoria usando a narrativa de que uma esposa que deseja receber mais carinho e atenção pode ser rotulada pelo marido como "carente e dependente". Não obstante, se o mesmo marido é quem deseja receber mais afeto, a esposa pode ser rotulada por ele como "indiferente e insensível". Ou seja, "uma forma de 
comunicação alienante da vida é o uso de julgamentos moralizadores que implicam que aqueles que não agem em consonância com nossos valores estão errados ou são maus" (ROSENBERG, 2006, p. 48).

O item negação da responsabilidade trata da compreensão sincera de que cada um de nós é responsável por seus próprios pensamentos, sentimentos e atos. $\mathrm{O}$ autor alerta que nossa linguagem facilita a negação de nossa responsabilidade pessoal e anuvia nossa consciência, exemplificando com o uso da expressão "fazer alguém sentir-se" - ex.: "Você me faz sentir culpado". Rosenberg (2006) observa que nos tornamos perigosos quando não temos consciência de nossa responsabilidade por nossos comportamentos, pensamentos e sentimentos e afirma que temos sempre a opção de fazer ou não fazer.

De acordo com autor, apresenta-se uma interessante lista de expressões comumente utilizadas no nosso dia a dia que negam a responsabilidade de nossos atos praticados incutindo aos outros a "culpa". Exemplos disso são: "Cheguei atrasada porque havia muito trânsito hoje"; "Não vou apresentar o trabalho na reunião porque é muita coisa para lembrar". Entende-se então que devemos primeiro silenciar o ruído dentro de nós mesmos, de modo a formar uma ideia clara do que queremos comunicar, antes de tomar alguém de assalto para expor essa comunicação.

Intentando clarificar melhor a realidade dos fatos, o autor sugere que haja a substituição da linguagem que indique falta de escolha por uma que assuma a possibilidade de escolha; ex.: "Eu trabalho neste lugar porque não tenho outra opção" pode-se substituir por: "Eu escolhi trabalhar nesta empresa que possui metas que exigem mais de mim do que eu consigo dar porque eu estava desempregado e tinha que me sustentar".

$\mathrm{O}$ ato de tentar forçar as pessoas a fazerem algo, geralmente com exigências ou ameaças, é uma forma de violência, que pode acarretar diversos sentimentos negativos, como os sentimentos de punição, culpa ou pressão. $\mathrm{O}$ autor sublinha que o medo de ser punido diminui a autoestima e a boa vontade da pessoa e "por trás de mensagens intimidadoras, estão simplesmente pessoas pedindo para satisfazermos suas necessidades" (ROSENBERG, 2006, p. 144).

O pensamento baseado em "quem merece o quê" traz à tona a ideia de que certos atos merecem recompensa e outros, punição. Deflagra-se, então, a ideia presumida de que Fulano agiu de determinada maneira por "maldade" e, por isso, demanda que haja alguma punição para fazê-lo se arrepender de tal ato. 
No concernente às raízes filosóficas e políticas, o autor explora que quanto mais os indivíduos forem instruídos a pensar em termos de julgamentos morais, o que invariavelmente implica que algo é errado e algo é correto, mais eles serão treinados a consultar instâncias exteriores, as autoridades, para conhecer a definição do que se constitui como o certo/errado, o bom/mau.

Pelo raciocínio exposto, torna-se claro que o uso da $\mathrm{CNV}$ possibilita uma socialização mais autêntica e empática, em face de que mostra uma rota que as pessoas possam seguir para viverem sua verdade pessoal sem limitar os outros, deixando que estes sejam eles mesmos. Conforme o postulado pela CNV, é possível aceitar o outro, mesmo não concordando com ele, quando nos tornamos capazes de enxergar a necessidade que há por trás das ações do outro. É fundamental para qualquer tipo de relacionamento discordar sem ódio, sem ironia e sem insultos. Pois, nenhuma pessoa se abre para receber um comunicado quando está diante de um ataque pessoal. Esse tipo de visão proporcionada pela $\mathrm{CNV}$ desenvolve maior confiança na relação, o que nos permite mostrar nossas vulnerabilidades sem temer sermos julgados por tais. Atenta-se para a imagem que muitas vezes queremos transmitir aos outros, a imagem do competente, do sagaz, do prestativo, do alegre etc., o que não raro não corresponde à nossa realidade interna.

Quando temos esse tipo de conduta, em geral, podemos conseguir esconder das outras pessoas partes de nossa existência, como: insegurança em determinada situação, necessidade de orientação, medo, raiva etc. Entretanto, esses aspectos ainda existem em nós e têm algum poder sobre nosso comportamento, o que pode levar a um relacionamento falso, onde escondemos nossa humanidade e não abrimos espaço para o outro revelar a sua. Assim, atacamos o outro para parecermos poderosos em vez de revelar nossa insegurança, e como consequência cada vez mais percebemos o outro como uma ameaça, especialmente em momentos de conflito. Em geral, nos momentos de conflito tendemos a "partir para a briga" e, assim, temos um grande gasto de energia e concentração em nos defender e atacar o outro. Neste cenário, busca-se ativamente o "culpado", o que implica dizer que alguém tem a culpa e está errado, assim, torna-se quase impossível que haja uma troca de informações sinceras, pois, dificilmente conseguiremos ouvir e sermos ouvidos realmente.

A proposta da CNV marca seu diferencial com a sua pretensão de sair dos comportamentos de ataque/defesa e, assim, partir rumo ao melhor resultado possível para todos. Portanto, ao fazer uso da CNV, a discussão pode servir como um meio para obter um resultado específico e evitar o agravamento de uma situação já difícil. Nota-se que as 
concepções da CNV estão de acordo com o postulado por Lewin (1978), que relata que o ideal é que a comunicação entre os integrantes de um grupo seja autêntica. Pois, segundo o autor, um grupo que não apresenta espaço para que seus integrantes possam ser autênticos e se comunicarem, pode desenvolver redes paralelas e informais externas ao grupo, o que esvazia a sua força.

Para que haja esse encontro sincero na relação, Rosenberg (2006) declara que é necessário receber o outro com empatia e atenção, captar a essência dos sentimentos da situação vivida e as necessidades e os pedidos que estão sendo expressos. Um artifício facilitador para a realização deste tipo de encontro pode ser o uso de parafrasear o que estamos escutando, pois, deste modo, há a oportunidade de desanuviar e reafirmar nossa compreensão do que estamos ouvindo e, assim, há a possibilidade do outro ouvir o que foi dito e o que foi compreendido. Chama-se a atenção para que os aspectos não verbais da comunicação não sejam negligenciados, pois são de grande importância no processo de comunicação.

De acordo com Rosenberg (2006), há uma mudança de atitude dependendo de como se fala, assim, conforme as orientações da CNV, deve-se falar de modo calmo e empático, falando pausadamente e com um tom de voz adequado, deve-se realizar perguntas simples e objetivas, que não abrem o tema para além daquilo que se quer saber, de modo a não constranger ou pressionar a pessoa. "Além de utilizarmos uma linguagem positiva, devemos evitar frases abstratas ou ambíguas e formular nossas solicitações na forma de ações concretas que os outros possam realizar" (ROSENBERG, 2006, p. 106).

\section{Considerações Finais}

Seja em um ambiente íntimo com a família e os amigos, ou em um ambiente mais formal, como o trabalho, grande parte de nossas expressões de sentimentos ou ideias são desprezadas ou repudiadas não por serem necessariamente ruins, mas por serem expressas de modo ineficiente ou inapropriado. Uma grande verdade sobre os relacionamentos humanos é que a maior parte das pessoas não imagina ou percebe o poder contido em suas palavras e no modo como elas são expressas. É esclarecido que a comunicação pode ocorrer com resultados indesejados porque é realizada de forma inadequada e ineficiente. No postulado da $\mathrm{CNV}$, nosso poder de comunicação reside necessariamente em todos os aspectos que compõem essa atividade. Portanto, uma comunicação eficaz inclui não apenas 
as palavras escolhidas, mas também o tom de voz, o tempo disponível para falar/ouvir e os aspectos não verbais.

A Comunicação Não Violenta é uma ferramenta bastante útil na resolução de conflitos, haja vista que, por intermédio de sua metodologia inovadora, leva em consideração o todo: comportamentos, sentimentos, percepções, necessidades pessoais de si e do outro. Dentro deste enquadramento mais realista, torna-se possível haver a empatia e a compassividade entre as pessoas envolvidas no diálogo, o que pode resultar na melhora da comunicação entre líder e liderado dentro da empresa.

A CNV inaugura um modo de comunicação que proporciona a possibilidade de uma conexão real em nossas interações, ao trazer a humanização à tona. Com todas as suas necessidades e vulnerabilidades, ela se torna uma valiosa ferramenta de resolução de conflitos e de habilidades sociais. Deste modo, a CNV pretende transformar o padrão tóxico de comunicação que afasta as pessoas umas das outras; pois, em sua lógica, cada conflito traz em si um modo de expressão de necessidades que não estão sendo atendidas. Observase, então, o movimento que retira a concentração da identificação do "culpado" e leva o foco para a identificação das necessidades dos envolvidos, fazendo com que o objetivo seja a busca de uma solução que atenda às necessidades das pessoas, ao invés de ser a busca de quem tem a culpa e merece punição. Tal mudança de pensamento e comportamento proporciona maior bem-estar para os trabalhadores e um ambiente organizacional muito mais acolhedor, autêntico, produtivo e eficiente.

\section{Referências}

ACUÑA, E.; FERNÁNDEZ, F. Análise de mudanças organizacionais: utilidades para políticas sociais. Revista de Administração Pública. Rio de Janeiro: FGV/EBAP, 1995.

ANDRADE, D. C. T., RAMOS, H. R. A Comparação entre Grupos Ocupacionais e Lotação Setorial/Departamental de uma IFES sob a Ótica da Socialização Organizacional. Revista Economia \& Gestão, v. 15, n. 39, p. 104-125, 2015.

ARAÚJO, L. C. G. de, GARCIA, A. A. Gestão de Pessoas: estratégias e integração organizacional. 2. ed. São Paulo: Atlas, 2010.

BENÍTEZ, Z. R. Os gerentes atuando como facilitadores da comunicação interpessoal para incrementar a criação do conhecimento organizacional. 2001. 251f. Dissertação (Mestrado em Administração) Universidade Federal de Santa Catarina. Florianópolis. Disponível em: 〈http://teses.eps.ufsc.br/Resumo.asp?1799〉. Acesso em: 04 nov. 17. 
BORGES, L. O, ALBUQUERQUE, F. J. B. Socialização organizacional. In: ZANELLI, J. C.; BORGES-ANDRADE, J. E.; BASTOS, A. V. B. (Org.). Psicologia organizacional e do trabalho no Brasil. Porto Alegre: Artmed, p. 331-356, 2004.

BRANDÃO, L. C. Trabalho em Equipe. Disponível em: <http://xa.yimg.com/kq/groups/24137146/2106347199/name/Texto_8_Trabalho_em_equ ipe\%5B1\%5D.pdf>. Acesso em: 28 out. 2017

CARDOSO, R. M.; MENDES, F. D. C. Linguagem: história, teoria e métodos. IN: YAMAMOTO, M. E.; VALENTOVA, J. V. (Orgs). Manual de Psicologia Evolucionista. Natal: EDUFRN, 2018.

CHIAVENATO, I. Recursos Humanos. São Paulo: Atlas, 1992.

CHIAVENATO, I. Recursos Humanos. São Paulo: Atlas, 2002.

CHIAVENATO, I. Gestão de pessoas: o novo papel dos recursos humanos nas organizações. Rio de Janeiro: Campus, 2004.

DAVIS, K; NEWSTRON, J. W. Comportamento humano no trabalho: uma abordagem organizacional. São Paulo: Pioneira Thomson Learning, 2001.

DUTRA, J.S. Gestão de Pessoas: modelos, processos, tendências e perspectivas. São Paulo: Atlas, 2006.

FELIPPE, M. I. Conflitos e Emoções. São Paulo, UNIP, 2012.

FIORELLI, J.O. Psicologia para Administradores. São Paulo: Atlas, 2000.

FISCHER, A. L.; DUTRA, J. S.; AMORIM, W. A.C. Gestão de pessoas: práticas modernas e transformação nas organizações. São Paulo: Atlas.2010.

FLEURY, M. T. L. As pessoas na organização. São Paulo: Editora Gente, 2002.

FLEURY, M.T.L; FISCHER, R. M. Cultura e poder nas organizações. São Paulo: Atlas, 2007.

FONSECA, J. A. Comprometimento Organizacional: implicações de mudança organizacional na Polícia Militar de Minas Gerais. Dissertação (Mestrado em Administração) - Centro de Pós Graduação e Pesquisa em Administração da UFMG, Belo Horizonte, 2000.

FUSTIER, M. O conflito na empresa. Martins Fontes 1982.

GHANI, A. K.; JAYAKABALAN, V.; SUGUMAR, M. Impact of advanced manufacturing technology on organizational structure. The Journal of High Technology Management Research, Elsevier Science, 2002.

GIL, A. C. Gestão de pessoas: enfoque nos papéis profissionais. São Paulo: Atlas, 2008. 
KATZ, D.; KAHN, R. L. Psicologia social das organizações. São Paulo: Atlas, 1974.

LACOMBE, F.J.M. Recursos humanos: princípios e tendências. São Paulo: Saraiva, 2005.

MACEDO FILHO, A. F. A Percepção e a comunicação no ambiente organizacional. São Paulo, UNIP, 2003.

OLIVEIRA, S.R.; ECCEL, C.S. Sociologia e cultura organizacional. In: PICCININI, Valmira Carolina; ALMEIDA, Marilis Lemos de, OLIVEIRA, Sidinei Rocha. Sociologia e administração. Rio de Janeiro: Elsevier, 2011.

OMS, Organização Mundial da Saúde. Empresas devem promover saúde mental de funcionários no ambiente trabalho. Disponível em: <https://nacoesunidas.org/omsempresas-devem-promover-saude-mental-de-funcionarios-no-ambiente-trabalho/>. Acesso em: 31 maio 2019.

PRATES, C. Doenças psíquicas aumentam no ambiente de trabalho. Disponível em: <https://www.atribuna.com.br/2.713/doen\%C3\%A7as-ps\%C3\%ADquicas-aumentam-noambiente-de-trabalho-1.18724> Acesso em: 31 maio 2019.

ROBBINS, S.P. Administração: mudanças e perspectivas. São Paulo: Saraiva, 2002.

ROBBINS, S. P. Fundamentos do comportamento organizacional. São Paulo: Pearson, 2010.

ROBBINS, S. P., DECENZO, D. A. TAYLOR, R.B. Fundamentos da Administração: conceitos essenciais e aplicações. São Paulo: Prentice Hall, 2004.

ROSENBERG, Marshall B. Comunicação não violenta. Técnicas para aprimorar relacionamentos pessoais e profissionais. 3. ed. São Paulo: Ágora, 2006.

SCHEIN, E. H. Psicologia organizacional. 3 ed. Rio de Janeiro: Prentice Hall do Brasil, 1982.

SILVA, A. H; FOSSA, M. I. T. O processo de socialização organizacional como estratégia de integração indivíduo e organização. Curitiba: Cadernos da Escola de Negócios, v.1, n. 11, p.17-28, 2013.

SILVA, L. N, NASCIMENTO, R. F; BOTELHO, M. A. S. A importância do programa de integração: um estudo da perspectiva dos gestores da empresa Lopes \& Cia. In: X Simpósio de Excelência em Gestão e Tecnologia. Rezende, Rio de Janeiro, 2013.

SINYASHIKI, O processo de socialização organizacional. In: FLEURY, M.T. L. et al. As pessoas na organização. São Paulo: Editora Gente, 2002.

TRINDADE, E.A.B.; CRUZ, V.S.; TRINDADE, D.P. A aplicação da técnica de comunicação não violenta $(\mathrm{CNV})$ no relacionamento entre líder e liderado em ambiente de

teleatendimento.

Disponível

em: 
< CAO82014/ARTIGO01-A-APLICACAO-DA-TECNICA-DE-COMUNICACAO-NAOVIOLENTA.PDF>. ACESSO EM: 23 MAR. 2017

VAN MAANEN, J. Processando as pessoas: estratégias de socialização organizacional. In: FLEURY, M. T. L. et al. Cultura e poder nas organizações. São Paulo: Atlas, 1996.

VIEIRA, E. F.; VIEIRA, M. M. F. Estrutura Organizacional e Gestão do Desempenho nas Universidades Federais Brasileiras. Revista de Administração Pública, Rio de Janeiro, v. 37, n.4, p. 899-920, 2003.

WAGNER III, J. A. Comportamento organizacional. Saraiva, 1999.

WATZLAWICK, P.; BEAVIN, J. H.; JACKSON, D. D. Pragmática da comunicação humana: um estudo dos padrões, patologias e paradoxo da interação. 17. ed. São Paulo: Cultrix, 2007. 